\title{
Separation of convective and stratiform precipitation for a precipitation analysis of the local model of the German Weather Service
}

\author{
I. Langer and E. Reimer \\ Institute for Meteorology, Free University of Berlin, Germany \\ Received: 13 July 2006 - Revised: 22 November 2006 - Accepted: 31 January 2007 - Published: 26 April 2007
}

\begin{abstract}
An improved independent precipitation data set with the horizontal resolution of $7 \times 7 \mathrm{~km}$ grid over central Europe was generated (Free University of Berlin (FUB)precipitation analysis). For scale dependent evaluation of the Local model (LM) of the German Weather service, the precipitation data were separated into convective and stratiform fractions. To analyse precipitation amounts an interpolation scheme is used which contains the data set of "present weather" (ww), rain gauges and cloud types from the WMOnetwork in hourly resolution from the year 1992 until 2004 together with satellite cloud types derived from Meteosat-7 data. The structural analyses of cloud classes from satellite data as well as clouds from the synoptic observations were used to develop a statistical interpolation procedure to build up an independent precipitation analysis in resolution corresponding to the LM grid.
\end{abstract}

\section{Introduction}

Rain tends to be a discontinuous variable. The correct computation of the expected amounts does not depend only on the accurate determination of the instantaneous rainfall rates, but also on the effective coverage of the rain gauges. From satellite data a homogeneous monitoring field can be derived, but an exact algorithm to attach definitely these data with precipitation amounts does not exist for mid-latitudes.

Satellite cloud data are highly important for the direct use in weather analysis and forecasting as well as in precipitation estimation and in comparison with model output. In contrast to the surface observations by weather services networks satellite data provides a complete horizontal and homogeneous data coverage, but it is necessary to transform radiances to quantitative cloud information. The cloud classi-

Correspondence to: I. Langer

(ines.langer@met.fu-berlin.de) fication and coverage derived from modern satellite data can be compared directly to model output data and can be used also to improve precipitation analyses. Most widely used are methods from geostationary satellites, partly in combination with microwave sensors or AVHRR channels (Cheng and Brown, 1995; Uddstrom and Gray, 1996; Vincente et al., 1998; Todd, 1999; Levizzani, 2001; Rosenow, 2001; Bennartz, 2003).

\section{Study area and WMO-synoptic data}

In order to compare precipitation from rain gauges and satellite data, the area between $\left(5.0^{\circ} \mathrm{E}-20.4^{\circ} \mathrm{E}, 39.6^{\circ} \mathrm{N}-55^{\circ} \mathrm{N}\right)$ has been selected. This area covers central Europe with a wide of 2.45 Mill. $\mathrm{km}^{2}$ (Fig. 1). For statistical analyses, data of cloud cover, cloud types, actual weather type and precipitation are taken from the German Weather service (DWD) in hourly intervals from the ground-based measurements. These data are used for the period of 1992 until 2003 (06:0018:00 UTC). (These data are from the daily transfer from the DWD to the Free University of Berlin.)

\section{Statistical analysis of synoptic precipitation data}

From the synoptic observations of "present weather" (ww) and cloud types at the WMO-synoptic stations (Fig. 1), a separation of convective and stratiform rain events at the time of observation or during the previous hour is possible. The numbering system of present weather which is used for the separation is given in Table 1 . Within the code section 50-55, 60-65 and 70-75, higher values represent higher intensity of precipitation. The code numbers 20-29 refer to events during the last hour before the observation time (VUB2, 1999). In the next step, the convective and stratiform clouds will be defined, which produce precipitation. Figure 2 shows the relative frequency of cloud classes for "convective" and

Published by Copernicus GmbH on behalf of the European Geosciences Union. 
Table 1. Code table of present weather used for separation of convective and stratiform rain events.

\begin{tabular}{lll}
\hline WMO-Code & convective rain events & stratiform rain events \\
\hline 17 & nearby thunderstorm & rain, snow not falling as showers \\
$20-24$ & & \\
$25-29($ except 28) & showers of rain, snow & drizzle \\
$50-59$ & & rain \\
$60-69$ & & solid precipitation not in showers \\
$70-75$ & & snow grains \\
77 & showery precipitation or with current or recent thunderstorm & \\
$80-99$ & & \\
\hline
\end{tabular}

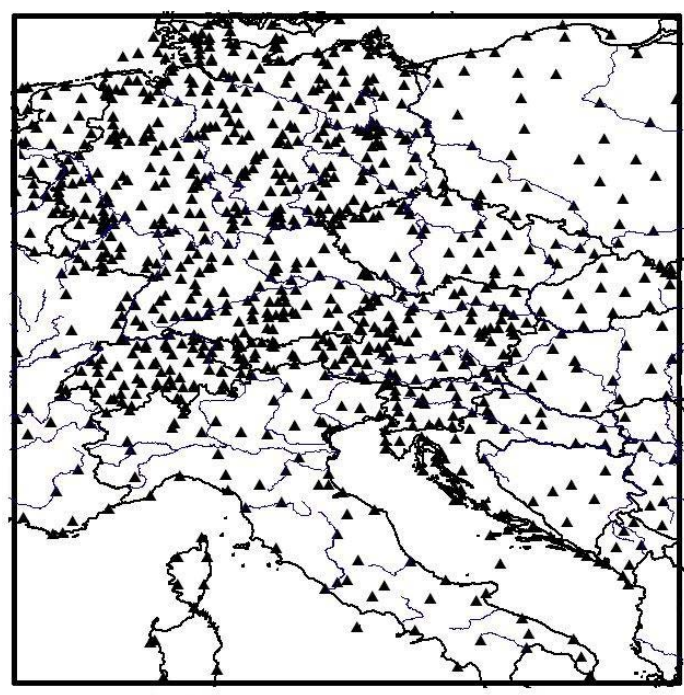

Fig. 1. Study area and distribution of the WMO-synoptic stations.

"stratiform" precipitation in Germany for low clouds derived from hourly values over a 12 year-period (1992-2003). All convective clouds including cumulonimbus are classified in the WMO-code classification as low clouds, because the cloud base is under $2500 \mathrm{~m}$ height.

The cloud classes for convective rainfall are as follows:

1. the cumulus class contains the cloud types: cumulus mediocris, cumulus congestus and ("cumulus and stratocumulus" by a weight of $33 \%$ ),

2. the cumulonimbus class includes: cumulonimbus calvus and cumulonimbus capillatus,

and for stratiform rainfall:

3. the stratus class contains the cloud type: stratocumulus, stratus nebulosus, stratus fractus and ("cumulus and stratocumulus" by a weight of $67 \%$ ),

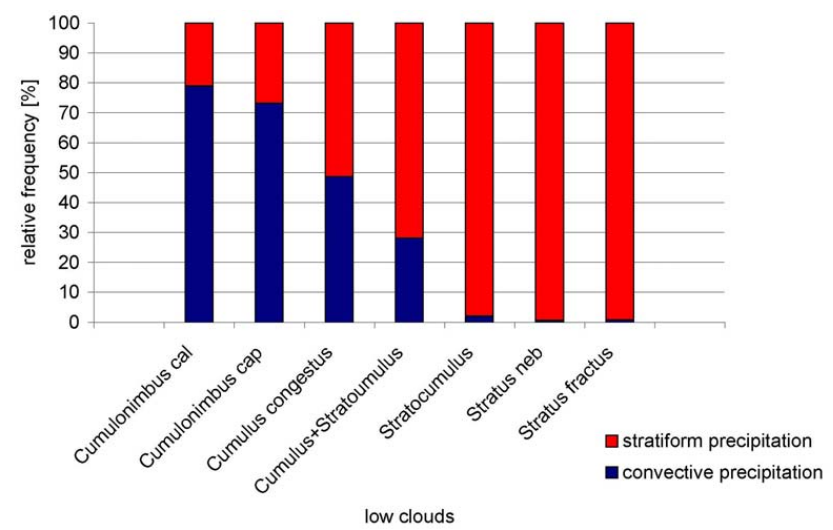

Fig. 2. Relative frequency of low clouds, each type distinguishing between convective and stratiform clouds, when rain is observed from hourly synoptic data for the years 1992 until 2003, for the German stations.

4. the nimbostratus class contains the cloud type: altostratus opacus or nimbostratus, altocumulus translucidus or altocumulus together with altostratus or nimbostratus. This class belongs to middle level clouds.

The "cumulus and stratocumulus" cloud type (WMO-key 8 of low clouds) is separated into convective and stratiform cases by evaluating the present weather information Statistical analysis (1992-2003) revealed that the weighting factor of this cloud type is associated with $67 \%$ of stratiform and $33 \%$ of this cloud type is convective. The results of the statistical analysis belong to the single point observations of the synoptic network. 


\section{Satellite data}

Meteosat-7 data with a temporal resolution of 30 minutes are archived from 1992 until present at the Free University of Berlin together with the derived products of "cloud coverage" and "cloud classes". The original resolution of the Meteosat IR data is $4 \times 4 \mathrm{~km}^{2}$ at the sub-satellite point, but only around $6 \times 8 \mathrm{~km}^{2}$ in mid-latitudes. Meteosat- 7 data are transformed into a geographic projection with an effective spatial resolution of $0.01^{\circ}$. For the correction of the sun's elevation, the cosine of the sun's distance to the zenith was used.

\subsection{Cloud classes from satellite data}

In order to determine the cloud classes and the cloud cover, the near-infrared $(0.5-0.9 \mu \mathrm{m})$ and the thermal infrared channel $(10.5-12.5 \mu \mathrm{m})$ from Meteosat-7 between 06:00 and 18:00 UTC were selected. The cloud classification from satellite data is based on the distribution of clouds in different heights (i.e. with different cloud top temperatures) and with different optical thicknesses in a bi-spectral histogram (Berger, 1992). One extreme case is the cloudless surface which should be the warmest and darkest area in the satellite image and the other extreme case is the cloud top of a cumulonimbus as the coldest and brightest area. The automated classification scheme tries to find those areas and builds test classes for other cloud types and calculates the arithmetic mean and the covariance for each class (Berger, 1992). For each pixel in the satellite image the probability of membership in the different classes is tested and the pixel is assigned to the class with the highest probability (Maximum Likelihood Method). The calculations are performed separately for land and sea as well as for clouds over land and over sea. Generally the comparison of satellite derived clouds and clouds observed by surface observation is difficult due to the fact that the clouds are observed from above and below the cloud layers. The comparison of precipitation derived from satellite and observed from rain gauges is generally difficult (Lutz, 2003). From Meteosat-7 data four clouds types in the high level were determined: cirrus spissatus, cirrus fibratus, cirrus spissatus cumulonimbogenitus and cirrostratus. The medium-high clouds are determined by two cloud types, altocumulus trans and altocumulus together with altostratus/nimbostratus. The low clouds are separated into six cloud classes: cumulus hum, cumulus med, cumulus/stratocumulus, cumulus congestus, stratus fractus (higher clouds not visible from the ground), cumulonimbus or nimbostratus. In fact, cumulonimbus and nimbostratus do not occur at the same time. If the nimbostratus has a cirrus layer above, the radiation characteristics due to the satellite channels are very similar to those of cumulonimbus and a separation of the cloud type is only possible with the help of the weather type from synoptic-based stations (Xie, 1995). Based on the results gained during GLOWA Elbe Experiment (Reimer et al., 2003), cloud types from satellite data
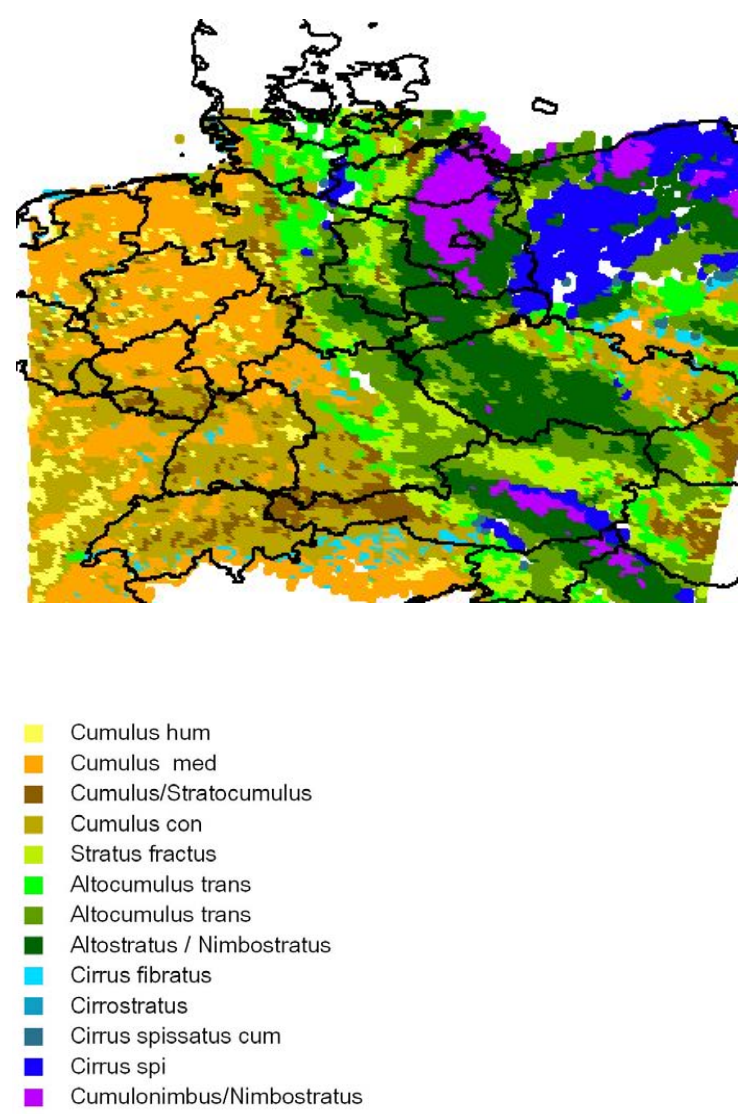

Fig. 3. Cloud classification from Meteosat data 12 August 2002, 13:00 UTC.

in comparison with synoptic data were statistically investigated. An example of the cloud types from Meteosat-7 data from 12 August 2002 at 13:00 UTC is shown in Fig. 3.

\section{Interpolation scheme for the precipitation analysis}

For the monitoring of rainfall and the use of rainfall data in model comparison, area-averaged fields are needed. Those fields can be derived by utilisation of satellite data. A weighting factor of precipitation for cloud types was generated by statistical analysis of satellite data and synoptic groundbased data. As a first step the interpolation scheme for the precipitation analysis is a simple linear interpolation Eq. (1), using the precipitation rate from observation and weights from cloud classes for different precipitation rates.

$f_{o}=\frac{\sum g_{i} f_{i}}{\sum g_{i}}$

$f_{o}=$ precipitation rate $[\mathrm{mm} / \mathrm{h}]$ at grid point

$g_{i}=$ weighting factor

$f_{i}=$ precipitation rate at observation station

Here the weighting factor $g_{i}$ is determined by quadrature of distance between grid point and each observation in 
Table 2. Expectation of the relative weighting function $w$ of cloud classes from Meteosat-7.

\begin{tabular}{lcccccccc}
\hline Precipitation [mm/h] & $0-0.9$ & $1-1.9$ & $2-2.9$ & $3-3.9$ & $4-4.9$ & $5-5.9$ & $6-6.9$ & $>7$ \\
\hline cumulus & 0.047 & 0.022 & 0.023 & 0.015 & 0.017 & 0.009 & 0.005 & 0.007 \\
cumulonimbus & 0.066 & 0.067 & 0.082 & 0.092 & 0.10 & 0.10 & 0.091 & 0.10 \\
cumulus (WMO-type 8) & 0.042 & 0.024 & 0.022 & 0.016 & 0.016 & 0.012 & 0.011 & 0.009 \\
stratusfractus & 0.10 & 0.025 & 0.021 & 0.005 & 0.008 & 0.008 & 0.005 & 0.0007 \\
stratus & 0.09 & 0.089 & 0.082 & 0.062 & 0.048 & 0.032 & 0.024 & 0.011 \\
stratocumulus (WMO-type8) & 0.064 & 0.042 & 0.034 & 0.025 & 0.017 & 0.013 & 0.014 & 0.005 \\
altocumulus & 0.055 & 0.064 & 0.066 & 0.079 & 0.076 & 0.050 & 0.056 & 0.049 \\
altocumulus with alto-/nimbostratus & 0.080 & 0.084 & 0.077 & 0.067 & 0.049 & 0.033 & 0.020 & 0.011 \\
\hline
\end{tabular}
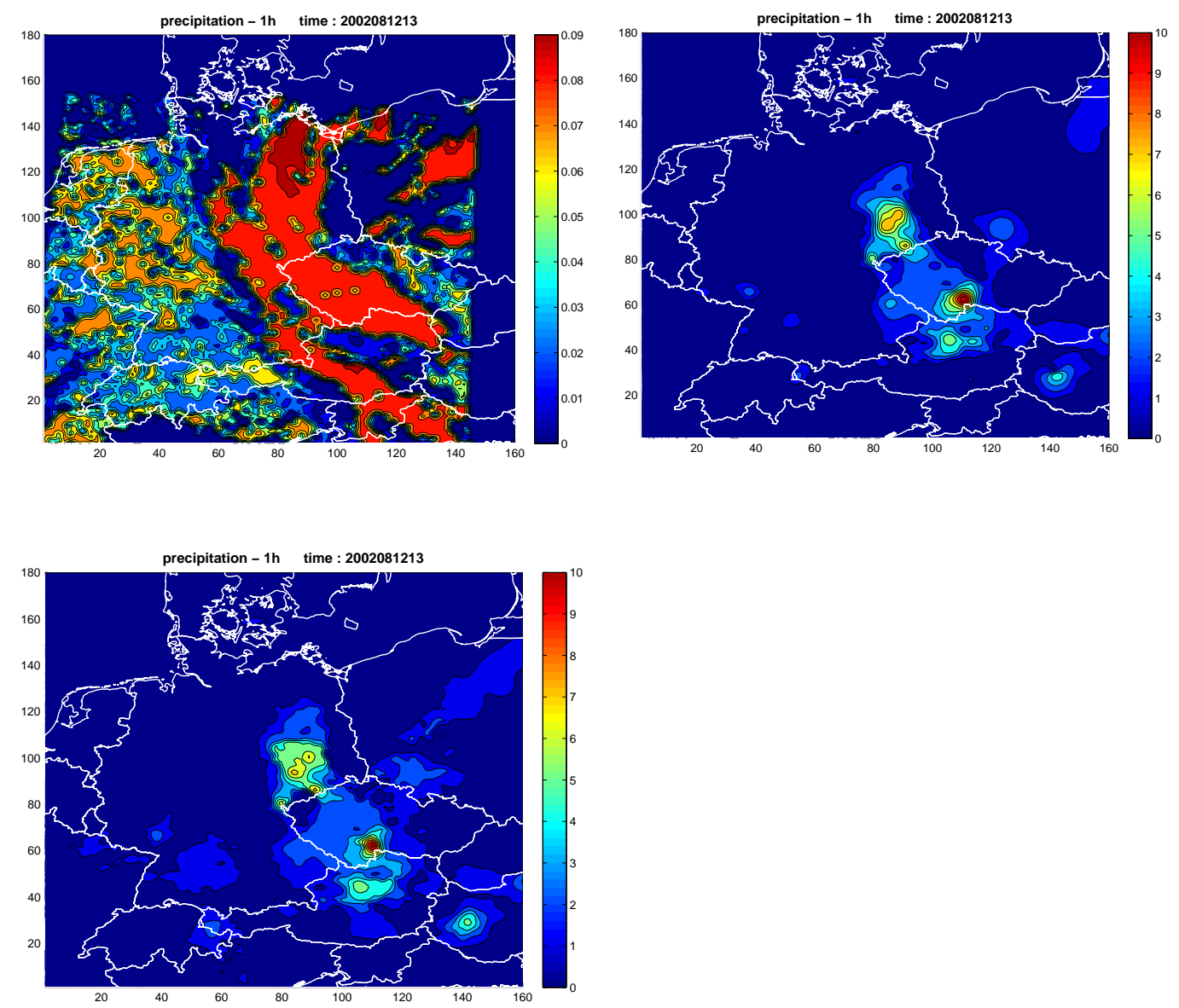

Fig. 4. (left above): Weight factor from Meteosat data at 12 August 2002, 13:00 UTC, (right above): Precipitation analysis [mm/h] without and with (below) weight factor from satellite data, 12 August 2002, 13:00 UTC.

Eq. (2), where $d_{i}$ denotes the distance between the position vector of the grid point $r o$ and the observation $r i$ and $w$ is the weight factor is given in Table 2 .

$g_{i}=\frac{1}{d_{i}^{2}|w o-w i|}, \quad d_{i=|r o-r i|}$

$w o=$ cloud weight at grid point

$w i=$ cloud weight at observation station
To introduce an anisotropic condition, the satellite born weights $w o$ and $w i$ for precipitation from Table 2 are used at the grid point from satellite cloud classes/types and at observation sites from observed or from satellite cloud classes/types. For each cloud class the local mean precipitation is determined and is normalized to the interval 0-1 in relation to all classes. 


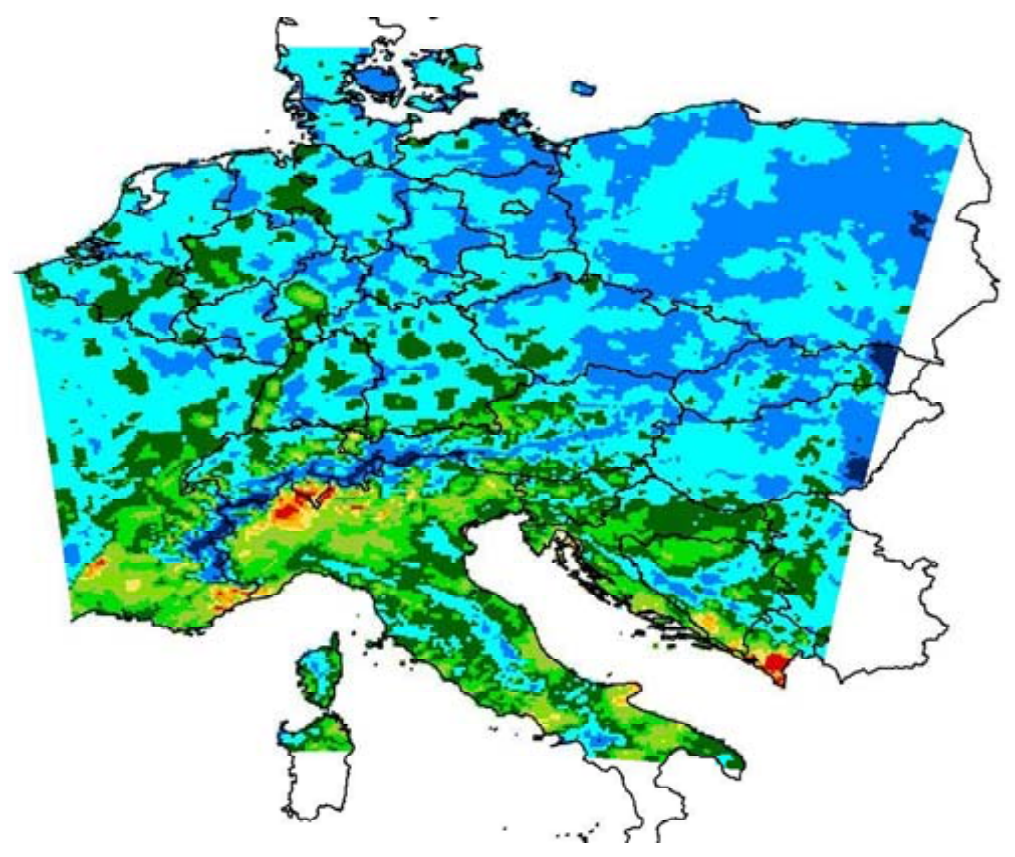

\section{stratiform}

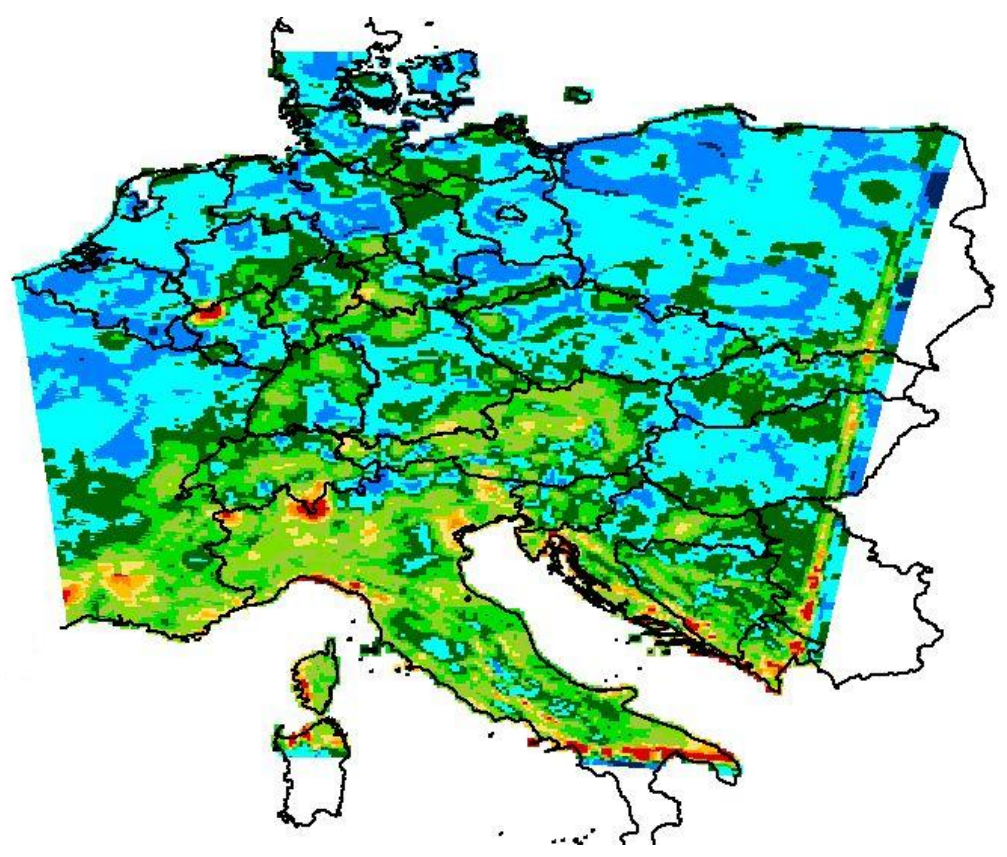

convective

- $0.01-0.1$

- $0.1-0.2$

$=0.2-0.3$

- $0.3-0.4$

$=0.4-0.5$

$=0.5-0.6$

$=0.6-0.7$

$=0.7-0.8$

$=0.8-0.9$

$=0.9-1$

- $>1$

Fig. 5. Mean absolute error between LM and FUB analysis 2002 from hourly data.

In Fig. 4 an example is shown for 3-hourly precipitation from 12 August 2002 at 13:00 UTC. In Fig. 4a the weights for precipitation from satellite are presented. Figure $4 \mathrm{~b}$ shows an example of an interpolated precipitation analysis. The satellite weighted analysis (Fig. 4a) shows more detailed structures, especially in the representation of the extreme values.
5.1 Example for precipitation analysis for LM verification

The precipitation output of the LM is separated in convective and large scale components. This separation includes the different processes and parameterisations of precipitation that are scaled and parameterized convective precipitation. In order to evaluate these processes, which take place at different 
scales, the separation fields of convective and stratiform precipitation by using synoptic WMO-data and the cloud classification derived from Meteosat are compared. A time series of precipitation data separated into stratiform and convective, at the horizontal resolution of $7 \mathrm{~km}$ and a temporal resolution of one and three hours is generated.

Figure 5 shows an example of the mean absolute error (MAE) between the LM-precipitation analysis and the FUB - precipitation analysis for convective and stratiform precipitation for the whole year 2002.

The results indicate that the stratiform precipitation (Fig. 5, below) has a larger error (yellow to red) in southern Europe. The mean absolute error for both, the convective and stratiform precipitation shows a greater error (red) over the Alpine region, particulary over Tessin and St. Gallen, which caused by the overestimation of the LM-precipitation. Generally the hilly areas like the Schwarzwald, Harz and the Eifel were overrated by the LM-precipitation.

The mean absolute error of convective precipitation in northern Europe shows a more uniform structure with a nearly consistent error by about 0.1 until 0.3 while the MAE of stratiform precipitation shows more a spotted structure by a mean absolute error by about 0.4 until 0.7 .

The model separation of precipitation into numerically resolved and subgrid-scale parameterised precipitation does not well correspond to a classification of precipitation into convective and stratiform components based upon SYNOP reports and satellite imagery.

\section{Conclusions and outlook}

For model forecast evaluation on hourly time-scale, a new observational dataset for precipitation over Central Europe has been computed. In this study, a method is described to generate a precipitation analysis for Central Europe separated in convective and stratiform precipitation. With the ground observation, of present weather, cloud types and clouds derived from satellite data, we separated nonprecipitating from precipitating clouds, which we then separated into stratiform and cumuliform clouds.

By applying the maximum-likelihood-method a bispectral cloud classification of Meteosat-7 data has been performed. Due to the low resolution of the Meteosat data many pixels were not classified correctly. Mainly cloud-free areas, areas with thin clouds and sparsely clouded areas were affected, while for cloud clusters and organized cloud systems the classification works much better.

With the help of the statistical analyses of cloud classes from satellite data, as well as clouds from the synoptic observations and measured precipitation we develop a statistical interpolation procedure to build up the precipitation analyses in resolution corresponding to the LM $7 \times 7 \mathrm{~km}$ grid of the German Weather Service.
For the statistical interpolation procedure of calculating convective and stratiform precipitation, the satellite data of cloud types were weighted into a precipitation probability of clouds with rain from a 12 years period. The results are weightings which represent potential rainfall rates and were apply for the precipitation analyses. The precipitation analysis with the weights of potential rainfall shows more detailed structures, particularly for the representation of extreme values. The main differences between FUB-precipitation analysis and LM-precipitation analysis can be found in stratiform precipitation where the south of Europe shows higher mean absolute error values. On the other hand the LM overestimates the convective precipitation only for higher hilly area and for the south of Europe.

The next step will be the development of a statistical interpolation procedure to build up an independent precipitation analysis in a resolution corresponding to the Local Model grid of $2.8 \mathrm{~km}$. New products are available after the launch of the first satellite of the new generation of geostationary satellites (Meteosat-8). These satellites provide 15-min products with a resolution at subsatellite point varying from 1.4 (high resolution VIS) to $4.8 \mathrm{~km}$ (IR) (Schmetz et al., 2002).

Acknowledgements. This work was funded by German DFG in the framework of the "Quantitative precipitation forecast SPP 1167" programme.

Edited by: S. C. Michaelides and E. Amitai

Reviewed by: anonymous referees

\section{References}

Bennartz, R. and Michelson, D.: Correlation of precipitation estimates from spaceborne passive microwave sensors and weather radar imagery for BALTEX, Int. J. Rem. Sens., 24, 723-739, 2003.

Berger, F. H.: Die Bestimmung des Einfusses von hohen Wolken auf das Strahlungsfeld und das Klima durch Analyse von NOAA AVHRR-Daten, Dissertation, Institut für Meteorologie, Freie Universität Berlin, Wiss. Met. Abh., Neue Folge Serie A 6, 3, 1992.

Cheng, M. and Brown, R.: Delineation of precipitation areas by correlation of METEOSAT visible and infrared data with radar data, Mon. Wea. Rev., 1123, 2743-2757, 1995.

Levizzani, V., Schmetz, J., Lutz, H.J., Kerkman, J., Alberoni, P. P, and Cervino, M.: Precipitation estimations from geostationary orbit and prospects for METEOSAT Second Generation, Meteorol. Appl. 8, 23-41, 2001.

Lutz, H.-J., Inoue, T., and Schmetz, J.: Comparison of a splitwindow and a multi-spectral cloud classification for MODIS observations, J. Meteorol. Soc. Japan, 81, 623-631, 2003.

Reimer, E., Oestreich, A., Koslowsky, D., and Langer, I.: Wolken und Niederschlag aus Satellitenmessungen: eine 11jährige Reihe für das ElbeEinzugsgebiet, Poster zur 6. DKT in Potsdam vom 22.9-25.9.03., 2003.

Reimer, E. and Scherer, B. : An operational meteorological diagnostic system for regional air pollution analysis and long-term 
modelling, in: Air Pollution Modelling and it Applications IX., edited by: van Doop, H., Plenum Press., 1992.

Rosenow, W., Güldner, J., and D. Spänkuch: The "satellite Weather" of the German Weather Servicean assimilation procedure with a spectral component, Proceedings of the 2001 EUMETSAT Data Users Conference, 541-545, 2001.

Schmetz, J., Pili, P., Tjemkes, S., Just, D., Kerkmann, J., Rota, S., and Ratier, A.: An introduction to Meteosat Second Generation (MSG), Bull. Amer. Meteorol. Soc., 83, 977-992, 2002.

Todd, M. C.: Estimation of daily rainfall over the upper Nile river using a continuously calibrated satellite infrared technique, Meteorol. Appl., 6, 201-210, 1999.
Uddstrom, M. and Gray, W.: Satellite cloud classification and rainrate estimation using multispectral radiances and measures of spatial texture, J. Appl. Meteorol., 35, 839-858, 1996.

Vincente, G. A., Scofield, R. A., and Menzel, W. P.: The operational GOES infrared rainfall estimation technique, Bull. Amer. Meteorol. Soc., 79, 1883-1898, 1998.

VUB2: Vorschriften und Betriebsunterlagen Nr. 2, Wetterschlüsselhandbuch Band A Schlüselform, 1999.

Xie, P. and Arkin, P. A.: An intercomparison of gauge observations and satellite estimates of monthly precipitation, J. Appl. Meteorol., 34, 1143-1160, 1995. 